\title{
On the 20th Anniversary of the Dysphagia Research Society
}

\author{
Reza Shaker
}

Published online: 15 February 2012

(C) Springer Science+Business Media, LLC 2012

It is with great pleasure that we present this special issue of Dysphagia in commemoration of the 20th Anniversary of the formation of Dysphagia Research Society (DRS). It is hard to believe that already 20 years have passed since that cold early November day in 1992 when over 230 of us, interested in the care of dysphagia patients and engaged in research to improve this care, congregated in the inaugural DRS meeting in Milwaukee, Wisconsin. Participants came from a number of countries from Europe, Asia, South and North America, and Australasia and represented disciplines such as Gastroenterology, Speech Language Pathology, Otolaryngology, Neurology, Rehabilitation Medicine, and Mechanical Engineering.

Over the past 20 years, the society has vigorously pursued its goals of enhancing and encouraging research pertinent to normal and disordered swallowing and related functions. It has attracted new investigators to the field and, more importantly, encouraged interdisciplinary research. It has effectively promoted the dissemination of knowledge related to normal and disordered swallowing and provided a multidisciplinary forum for presentation of research while fostering new methodologies and instrumentation in dysphagia research and its clinical applications. These goals were in concordance with those of our journal, which soon became the official organ of the Dysphagia Research Society and other dysphagia-related societies that subsequently were formed in Japan and Europe.
It has been a productive and rewarding partnership. The Dysphagia journal and the Society have been effective partners to promote the field. Through this partnership, patients, clinicians, and investigators have been heard. New findings in research and treatment have been presented. Many important milestones have been passed. Parallel to the growth of the journal and the Society, dysphagia care and research has emerged from obscurity, the multidisciplinary nature of swallowing and its disorders has been recognized, and the importance of comprehensive training that incorporates the entire field of deglutition has been acknowledged. There is talk about the need for development of a new discipline: "Deglutology," a unique discipline serving as a home for clinicians and investigators irrespective of their original field of training. This discipline would focus specifically on advancing the field of deglutology for the benefit of the ever-increasing number of dysphagia patients world-wide in need of better prevention and treatment.

A great deal has been accomplished in 20 years and these accomplishments have paved the way to meet the challenges ahead. We congratulate the DRS members and leadership for their accomplishments and service to the field of deglutition and deglutition disorders. Happy 20th anniversary.

\section{Reza Shaker MD}

R. Shaker $(\bowtie)$

Division of Gastroenterology and Hepatology,

Medical College of Wisconsin, 9200 West Wisconsin Avenue,

FEC 4510, Milwaukee, WI 53226, USA

e-mail: rshaker@mcw.edu 